\title{
Sistem Informasi Manajemen Berbasis Web pada Usaha Mikro Kecil Dan Menengah (UMKM) (Studi Kasus: UMKM Sumber Jokotole, Socah, Bangkalan)
}

\author{
Issa Dyah Utami ${ }^{1}$, Iwan Santosa ${ }^{2}$, Rulli Annisa ${ }^{1}$, Irda Rebecca Simanjuntak ${ }^{1}$, Ulfi Atika Permatasari ${ }^{1}$, Nur \\ Faizah $^{1}$ \\ ${ }^{1}$ Jurusan Teknik Industri dan Mesin, Fakultas Teknik, Universitas Trunojoyo Madura \\ ${ }^{2}$ Prodi Informatika, Fakultas Tekik Universitas Trunojoyo Madura \\ i.d.utami@trunojoyo.ac.id
}

\begin{abstract}
The Sumber Jokotole SMEs produces fish crackers with basic ingredients from fish which are fishery products from Madura. During this time, the data on the sale of products and the purchase of raw materials have not been archived, so there is some data that is lost or damaged. When the data is needed to check the number of sales, the number of purchases, looking for stock of sales and purchases, and profits, the manager of the SMEs has difficulty tracking the data. Hence the management of a good and accurate sales and financial administration system is one of the strategies that can be applied by the SMEs in dealing with competition in the ASEAN Economic Community $(A E C)$. This research aims to aid SMEs Sumber Jokotole in managing the administration system and business processes by designing a web-based management information system (SIM) that can be accessed through computers and smartphones. The information system will provide benefits for producers, suppliers and consumers to manage business processes in the fish cracker SMEs.
\end{abstract}

Keywords: Management information system, Small and medium sized enterprises, marketing

Abstrak. UMKM Sumber Jokotolememproduksi kerupuk ikan dengan bahan dasar dari ikan yag merupakan hasil perikanan dari Madura. Selama ini, data-data tentang pejualan produk dan pembelian bahan baku belum diarsipkan, sehingga ada sebagian data yang hilang atau rusak. Pada saat data tersebut dibutuhkan untuk melakukan pengecekan tentang jumlah penjualan, jumlah pembelian, mencari stok penjualan dan pembelian, dan laba, pengelola UMKM mengalami kesulitan untuk menelusuri data tersebut. Pengelolaan sistem administrasi penjualan dan keuangan dengan baik dan akurat merupakan salah satu strategi yang dapat diterapkan oleh UMKM dalam menghadapi persaingan diera MEA. Untuk membantu UMKM Sumber Jokotole dalam mengelola sistem administrasi dan proses bisnisnya, penelitian ini perlu merancang sistem informasi manajemen (SIM) berbasis web yang dapat diakses melalui komputer dan smartphone. Sistem informasi akan memberikan manfaat bagi produsen, supplier maupun konsumen untuk mengatur proses bisnis pada UMKM kerupuk.

Kata Kunci: Sistem informasi manajemen, Usaha mikro kecil dan menengah, pemasaran

\section{Pendahuluan}

Usaha Mikro Kecil dan Menengah (UMKM) Sumber Jokotole yang berlokasi di Desa Kauman, Kecamatan Socah, Bangkalan, Madura memproduksi kerupuk dengan bahan utama ikan. UMKM ini berdiri sejak tahun 2010, dan satu-satunya UMKM kerupuk di Socah yang sudah mendapat ijin dari Departmen Industrian dan Tenaga Kerja dan juga Departmen Kesehatan dengan diperoleh nomor Pengusaha Industri Rumah Tangga (PIRT) 2.02.35.26.21.0095.18. UKM Sumber Jokotole terletak di desa Kauman Kecamatan Socah. Pada UKM Sumber Jokotole. Selama ini, data-data tentang pejualan produk dan pembelian bahan baku belum dibukukan dan diarsipkan, sehingga ada sebagian data yang hilang atau rusak. Pada saat data tersebut dibutuhkan untuk melakukan pengecekan tentang jumlah penjualan, jumlah pembelian, mencari stok penjualan dan pembelian, dan laba, pengelola UMKM mengalami kesulitan untuk menelusuri data tersebut. Data penjualan hanya dicatat dari beberapa transaksi saja sehingga omset perbulannya terdapat belum diketahui secara pasti. Biaya proses 
produksi ditentukan berdasarkan perkiraan saja sekitar $10 \%$ dari hasil penjualan, tanpa melalui perhitungan pasti dari pembelian bahan baku, pembayaran gaji tenaga kerja dan biaya overhead.

Persaingan didunia usaha, terutama diera perdagangan bebas Masyarakat Ekonomi Asean (MEA) ini, UMKM dituntut untuk mampu bersaing dengan UMKM dari dalam dan luar negeri untuk meningkatkan hasil penjualan (Fionita, 2015). Pengelolaan sistem administrasi penjualan dan keuangan dengan baik dan akurat merupakan salah satu strategi yang dapat diterapkan oleh UMKM dalam menghadapi persaingan tersebut. Sistem informasi adalah satu kesatuan data olahan yang terintegrasi dan saling melengkapi yang menghasilkan data olahan, baik dalam bentuk gambar, suara maupun tulisan (Rusdiana \& Irfan, 2014). Menurut O’Brien (2002), sistem informasi manajemen adalah sistem terpadu yang menyediakan informasi untuk mendukung kegiatan operasional, manajemen, dan fungsi pengambilan keputusan dari suatu organisasi. Untuk membantu UMKM Sumber Jokotole dalam mengelola pengelolaan permintaaan (managing demand) untuk menunjang pengelolaan hubungan konsumen (Ginting, 2011), sistem administrasi dan proses bisnisnya, perlu diterapkan siste informasi manajemen (SIM). Penerapan SIM ini bisa dilakukan dengan membuat database hasil penjualan, dan biaya produksi sehingga data akan tersusun rapi dan mudah untuk melakukan pengontrolan dan evaluasi yang dibutuhkan. Sistem informasi berbasis web yang dapat diakses melalui komputer dan smartphone. Sistem informasi akan memberikan manfaat bagi produsen, supplier maupun konsumen untuk mengatur proses bisnis pada UMKM kerupuk.

\section{Metode Penelitian}

Penelitian ini dilakukan di UMKM Sumber Jokotole yang berada di Jl. Kauman II/61 Socah, Bangkalan, Madura. Pelaksanaan penelitian ini dilakukan selama delapan bulan yaitu mulai dari observasi lapangan, pengumpulan data hingga penyusunan laporan. Variabel dalam penelitian ini antara lain: Sistem Sistem Informasi Penjualan, Sistem Informasi Produk, dan Sistem Informasi Keuangan. Data dikumpulkan melalui studi pengamatan, peninjauan secara langsung ke lokasi penelitian, pengumpulan dokumen atau data-data yang dilakukan langsung ke UMKM Sumber Jokotole dan studi pustaka pengambilan sebagai perbandingan dan referensi penelitian.

Berikut ini langkah-langkah analisa sistem Robby (2009):

1. Analisis kebutuhan dilakukan setelah melakukan studi lapangan, pada tahap ini dilakukan pengamatan terhadap masalah yang ada di UMKM kerupuk untuk mencari solusi terhadap permasalahan yang ada contohnya manajemen proses bisnis seperti keuangan, penjualan, dan pemasaran.

2. Menentukan User, dalam SIM ini terdapat beberapa user yang bisa memakai dan setiap user memiliki hak akses berbeda-beda. Disini di tentukan memiliki tiga user yaitu admin, produsen dan konsumen.

3. Membuat Fitur, pada tahap ini, dilakukan penentuan fitur-fitur untuk setiap user contohnya user admin, memiliki fitur yang lengkap seperti mengelola penjualan, menambah produk, dan memantau proses bisnis yang ada di sistem informasi.

Alat yang digunakan dalam penelitian adalah seperangkat komputer yang dilengkapi perangkat lunak pendukung, Software Sybase Power Designer, Software Xampp, Software Sublime Text

\section{Perancangan Sistem dan Implementasi 3.1 Perancangan model konseptual}

Gambar 1 menunjukkan Use Case Admin dari basisdata UKM Sumber Jokotole. Berdasarkan pada gambar 1 terdapat aktivitas yang bisa dilakukan oleh Admin. Admin disini mengelola data dari server dan mengelola data yang sudah diinputkan oleh pelanggan. Admin bisa mengelola produk (menambah data produk, mengedit data produk, dan menghapus data produk, update stok produk, melihat data pelanggan, melihat data pembelian,mengelola data admin (menambah data admin, mengedit data admin, dan menghapus data admin), mencetak laporan pembelian. 


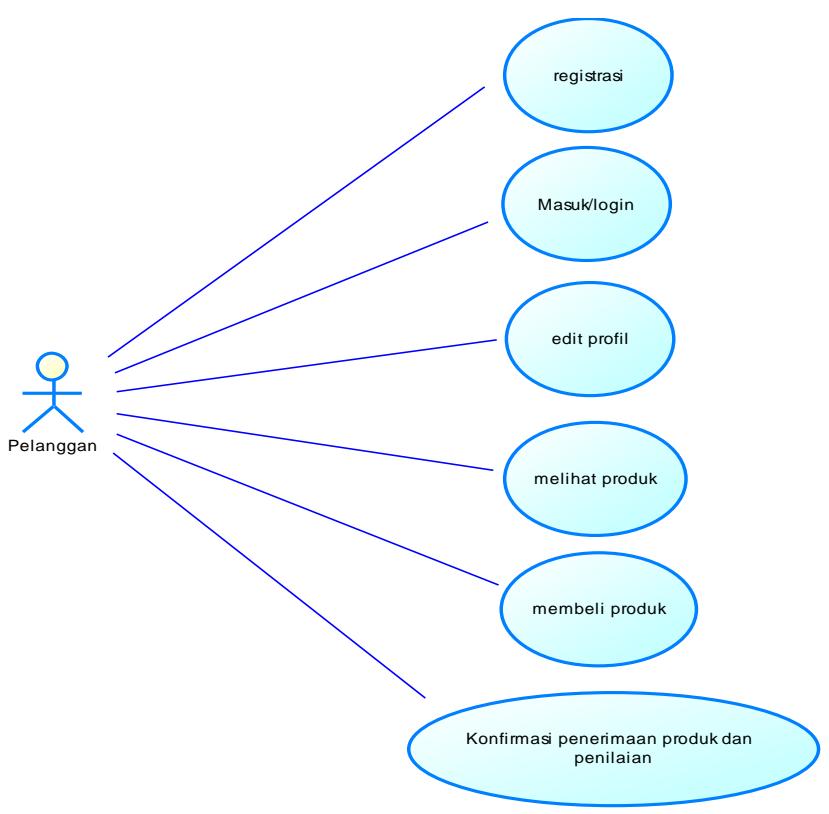

Gambar 1. Use Case Admin

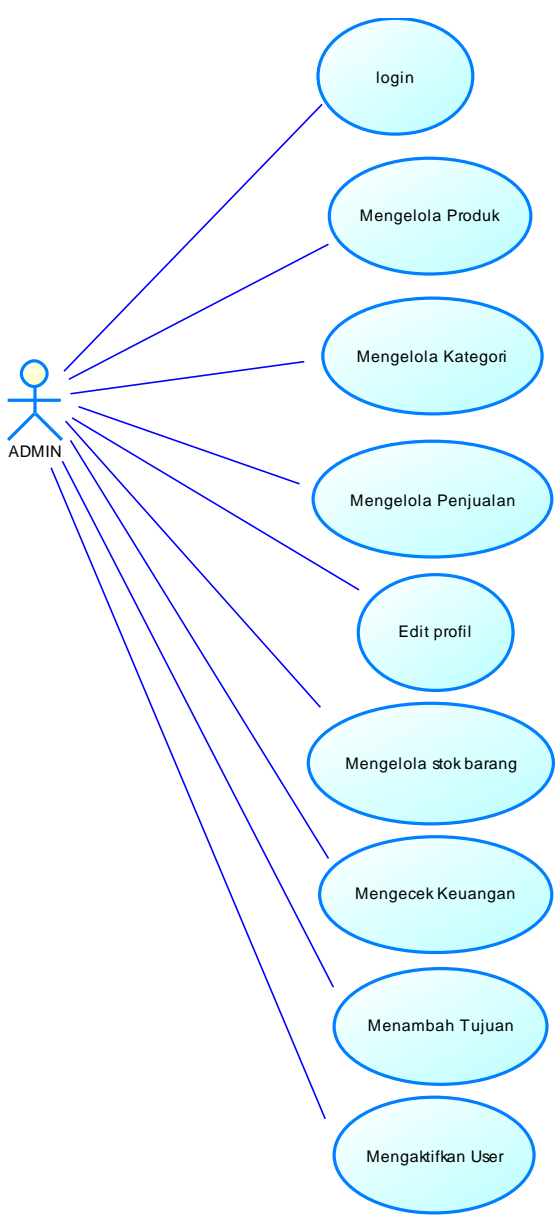

Gambar 2 Use Case Pelanggan

Gambar 1 menggambarkan Use Case Pelanggan dari basisdata UKM Sumber Jokotole. Pelanggan harus melakukan registrasi terlebih untuk untuk bisa mendapatkan username dan password guna melakukan login. Setelah melakukan login pelanggan dapat melihat profil toko, pelanggan juga dapat melihat produk yang ada di aplikasi. Selain itu pelanggan bisa melakukan pembelian apabila ada barang yang sesuai dengan keinginan. Barang yang sudah di pilih akan disimpan di keranjang belanja dan pelanggan melakukan konfirmasi pembelian.

Gambar 3. merupakan activity diagram dari basisdata UKM Sumber Jokotole. Gambar 3 merupakan activity diagram menjelaskan tentang aktifitas yang bisa dilakukan oleh admin, supplier dan pelanggan. Admin dapat melakukan login apabila bisa maka admin bisa masuk ke dalam web, kemudian masuk ke halaman utama web yang berisi sekilas UKM Sumber Jokotole dan produk, lalu bisa masuk ke halaman admin yang berisi tentang pengelolaan bisnis seperti produk, bahan baku, keuangan, dll pada UKM Sumber Jokotole. Supplier bisa melakukan login apabila supplier bisa maka supplier bisa masuk ke web, jika supplier tidak bisa login maka supplier harus daftar terlebih dahulu, kemudian masuk ke halaman utama web kemudian bisa masuk ke halaman supplier yang bisa mengelola menginputkan bahan baku. Dan pelanggan hanya bisa membeli produk pada situs web utama apabila sudah memiliki akun dan telah diaktifkan oleh admin. Kemudian yang terakhir melalukan pembayaran secara langsung. 


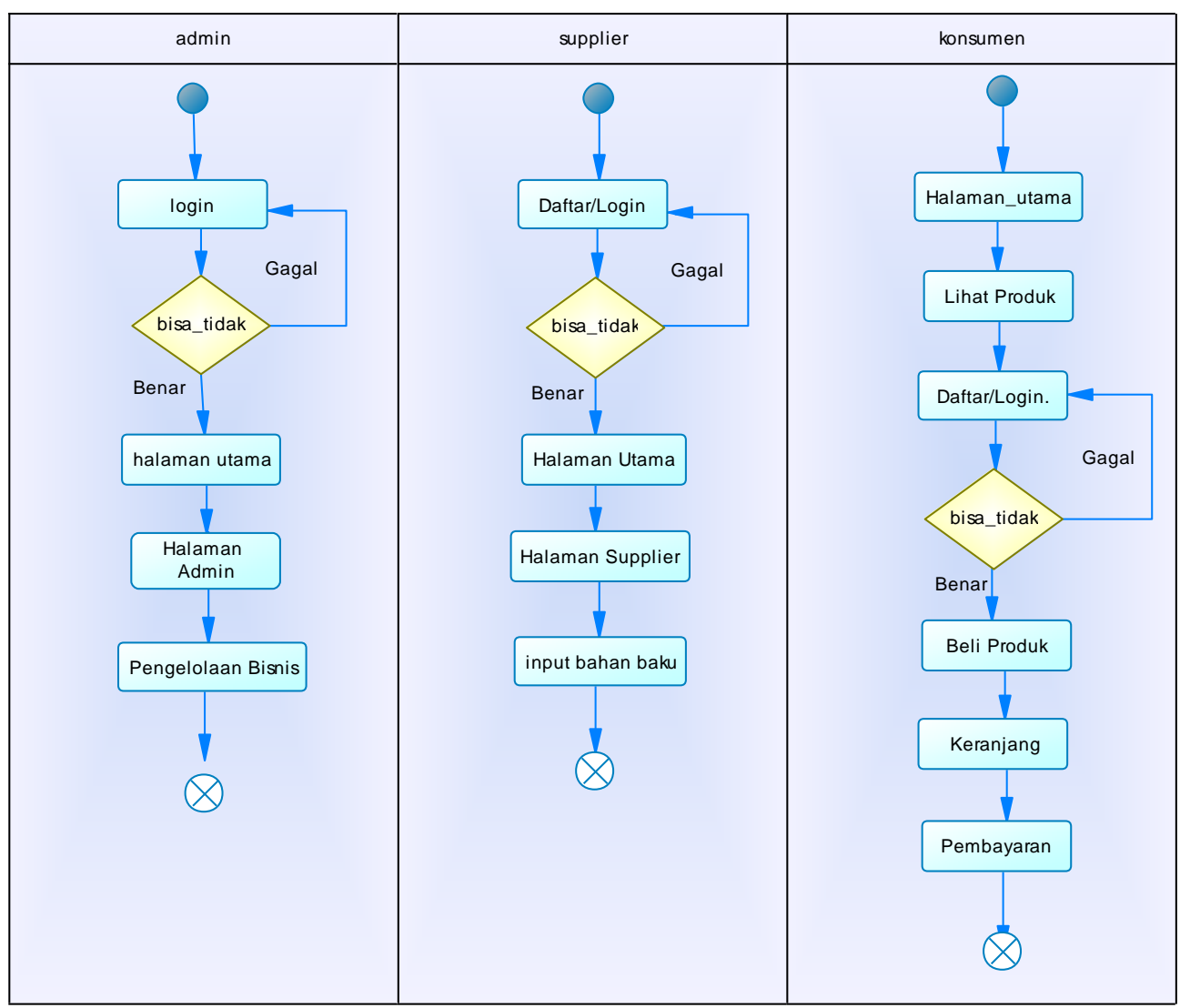

Gambar 3. Activity Diagram

Gambar 4 merupakan Conceptual Data Model dari basis data (Gat, 2015) UKM Sumber Jokotole. Dalam membuat sebuah CDM peneliti harus mengetahui hubungan kardinalitas antar entity yang akan dimasukkan dalam CDM tersebut. Pada CDM diatas hubungan kardinalitasnya dapat diuraikan sebagai berikut:

1. User dan bahan_baku mempunyai hubungan kardinalitas relasi one to one.

2. User dan transaksi mempunyai hubungan kardinalitas relasi one to many.

3. User dan konfirmasi mempunyai hubungan kardinalitas relasi one to many.

4. Transaksi dan tujuan mempunyai hubungan kardinalitas relasi one to one.

5. Transaksi dan ongkir mempunyai hubungan kardinalitas relasi one to many.

6. Produk dan kategori mempunyai hubungan kardinalitas relasi one to many.

7. Produk dan konfirmasi mempunyai hubungan kardinalitas relasi one to one.

8. User dan keuangan mempunyai hubungan kardinalitas relasi one to many 

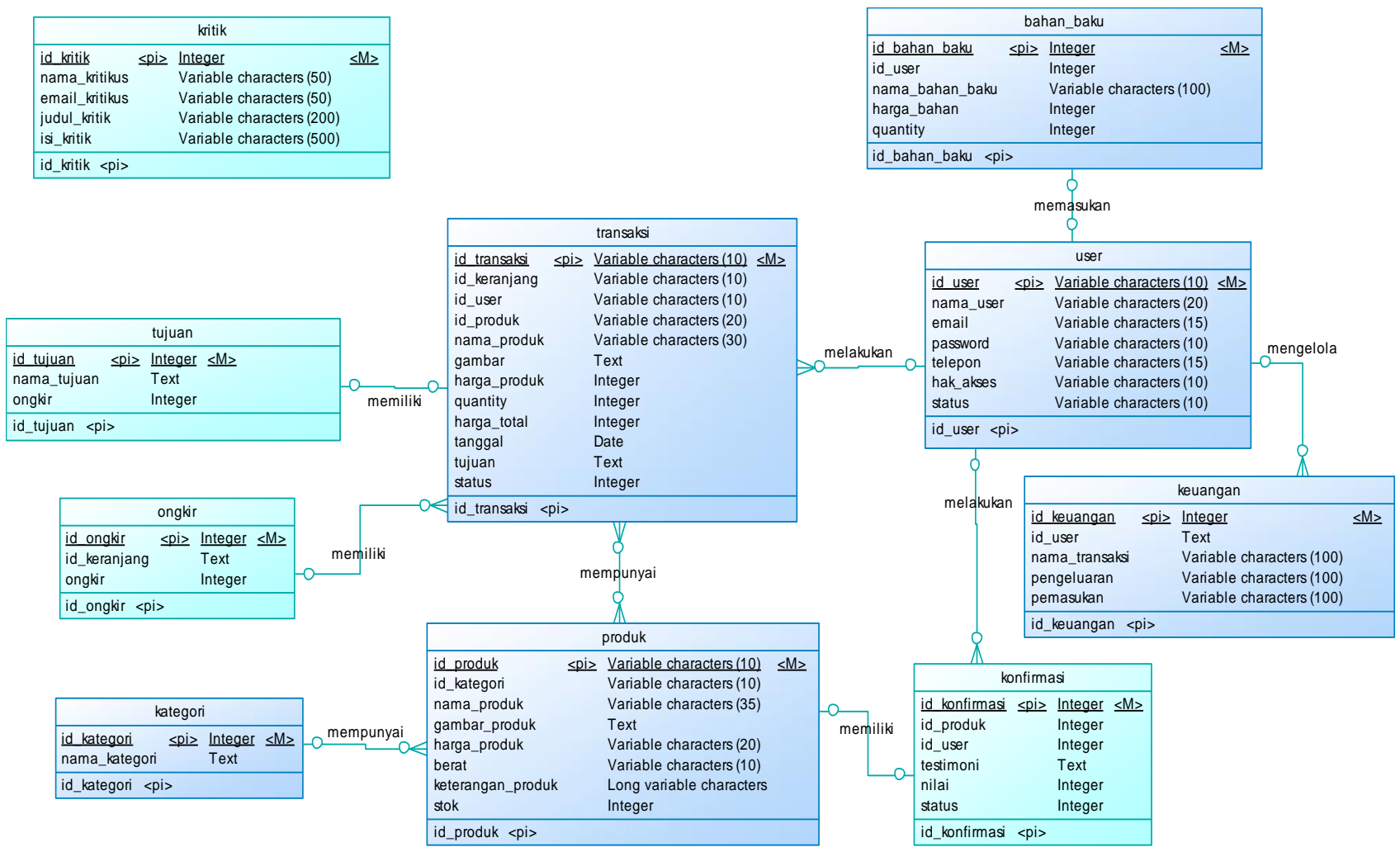

Gambar 4. Conceptual Data Model

Gambar 5 menunjukkan Physical Data Model (PDM) dari basis data UKM Sumber Jokotole. PDM dibuat berdasarkan CDM yang sudah peneliti buat pada Sybase power designer. PDM dibuat dengan melakukan generate into physical data model pada CDM. Penjelasan tentang PDM tersebut adalah sebag berikut:

1. Hubungan kardinalitas pada entity user dan entity bahan_baku adalah one to one sehingga atribut id_user yang menjadi primary key pada entity user akan menjadi foreign key pada entity bahan_baku.

2. Hubungan kardinalitas pada entity user dan entity transaksi adalah one to many sehingga atribut id_user yang menjadi primary key pada entity user akan mejadi foreign key pada entity transaksi.

3. Hubungan kardinalitas pada entity user dan entity konfirmasi adalah one to many sehingga atribut id_user yang menjadi primary key pada entity user akan menjadi foreign key pada entity konfirmasi.

4. Hubungan kardinalitas pada entity transaksi dan tujuan adalah one to one sehingga atribut id_transaksi yang menjadi primary key pada entity transaksi akan menjadi foreign key pada entity tujuan.

5. Hubungan kardinalitas pada entity transaksi dan entity ongkir adalah one to many sehingga atribut id_transaksi yang menjadi primary key pada entity transaksi akan menjadi foreign key pada entity ongkir.

6. Hubungan kardinalitas pada entity produk dan entity kategori adalah one to many sehingga atribut id_produk yang menjadi primary key pada entity produk akan menjadi foreign key pada entity kategori.

7. Hubungan kardinalitas pada entity produk dan entity konfirmasi adalah one to many sehingga atribut id_produk yang menjadi primary key pada entity produk akan menjadi foreign key pada entity konfirmasi.

8. Hubungan kardinalitas pada entity user dan entity keuangan adalah one to many sehingga atribut id_user yang menjadi primary key pada entity user akan menjadi foreign key pada entity keuangan. 


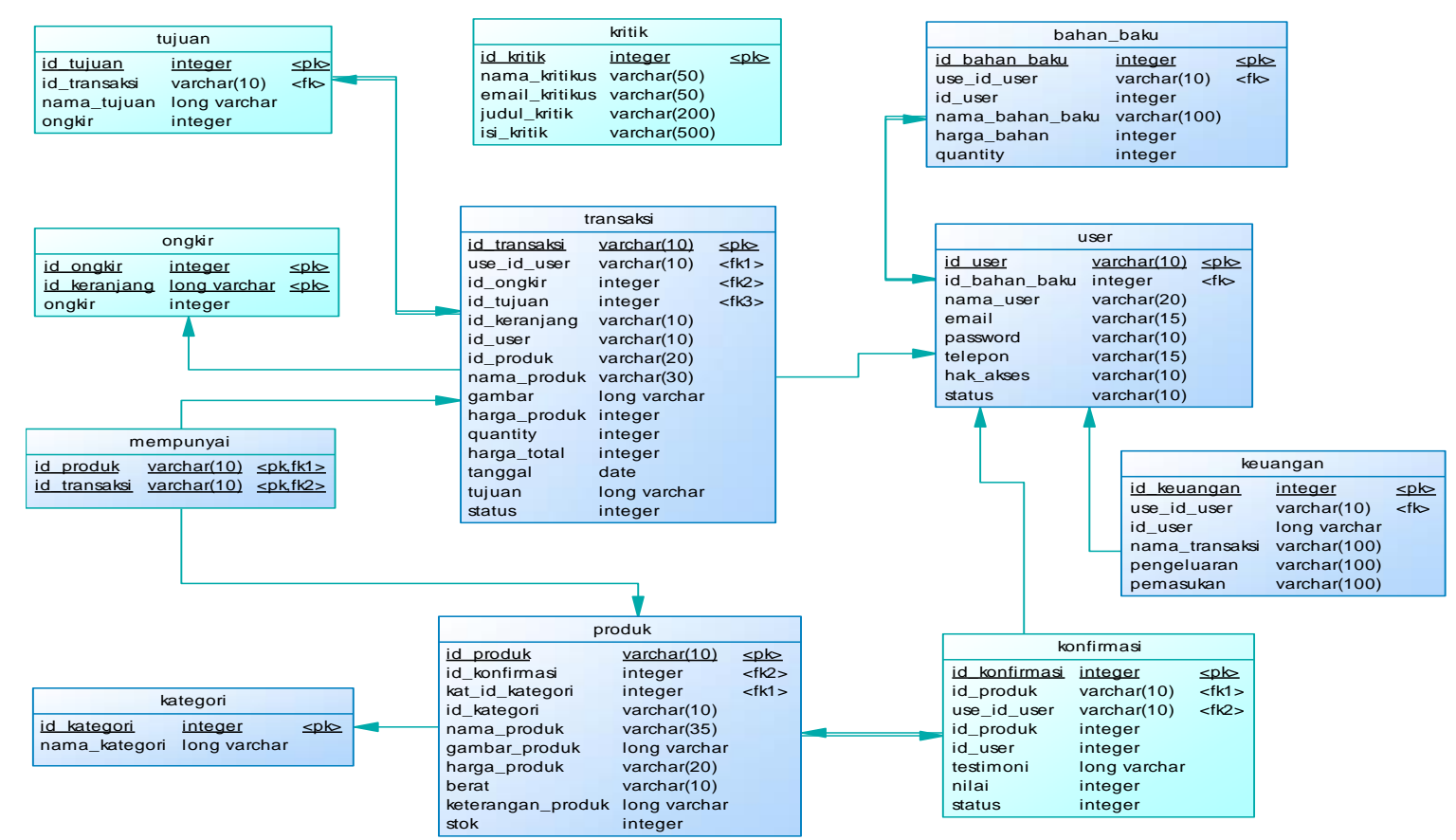

Gambar 5. Physical Data Model

\section{Hasil Penerapan Desain}

Hasil penerapan desain SIM ditunjukkanpada Gambar 6 hingga Gambar 11, yaitu halaman awal, pemesanan produk, keranjang belanja, pembayaran, keuangan dan bahan baku pada UKM Sumber Jokotole.
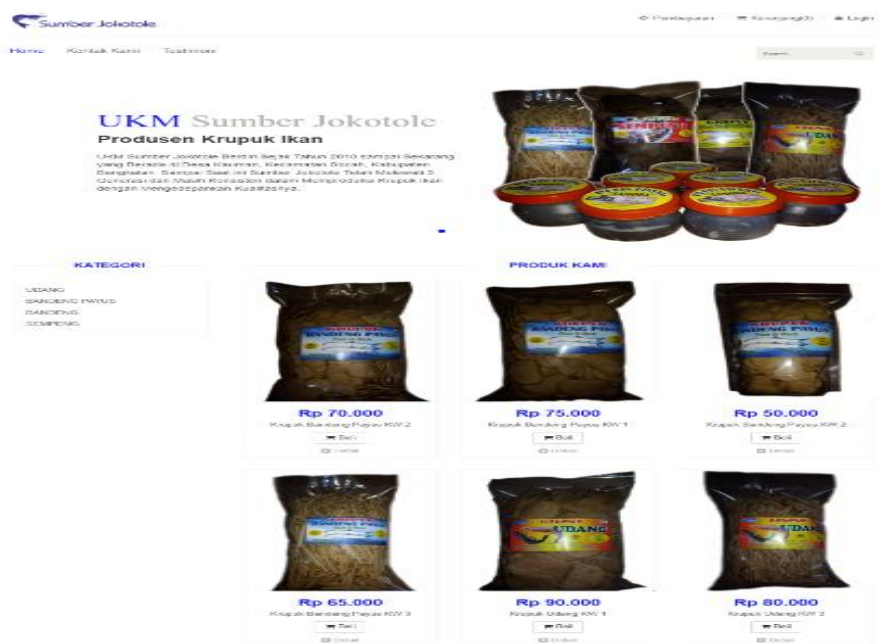

Gambar 6. Halaman Awal

Setelah konsumen melakukan registrasi pada situs jokotole, maka konsumen bisa melakukan pembelian yang telah tersedia dalam situs tersebut dan berisi tentang sekilas UKM Sumber Jokotole produsen krupuk ikan dan bisa memilih kategori kerupuk yang telah disediakan sesuai dengan keinginan konsumen. 
Fsimo

Home Kontak Kami Testmoni

KATEGORI

UDANG

BANDENG PAYUS

BANDENG

SEMPENG

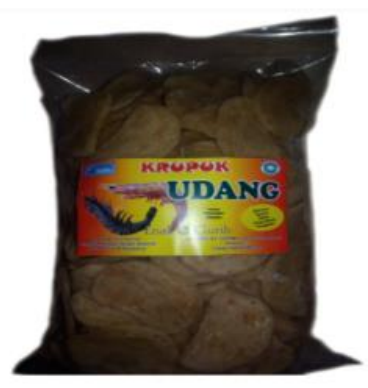

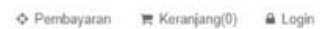

Krupuk Udang KW

Rp 90.000

Stok: 20

Berat: $1 \mathrm{Kg}$

Deskripsi: tetbuat dari udang

\section{Gambar 7. Pemesanan Produk}

Konsumen bisa memesan produk sesuai dengan keinginannya dan juga bisa melihat detail untuk lebih lengkapnya pada produk kerupuk tersebut, kemudian bisa melakukan pemesanan jika sesuai dengan keinginannya.

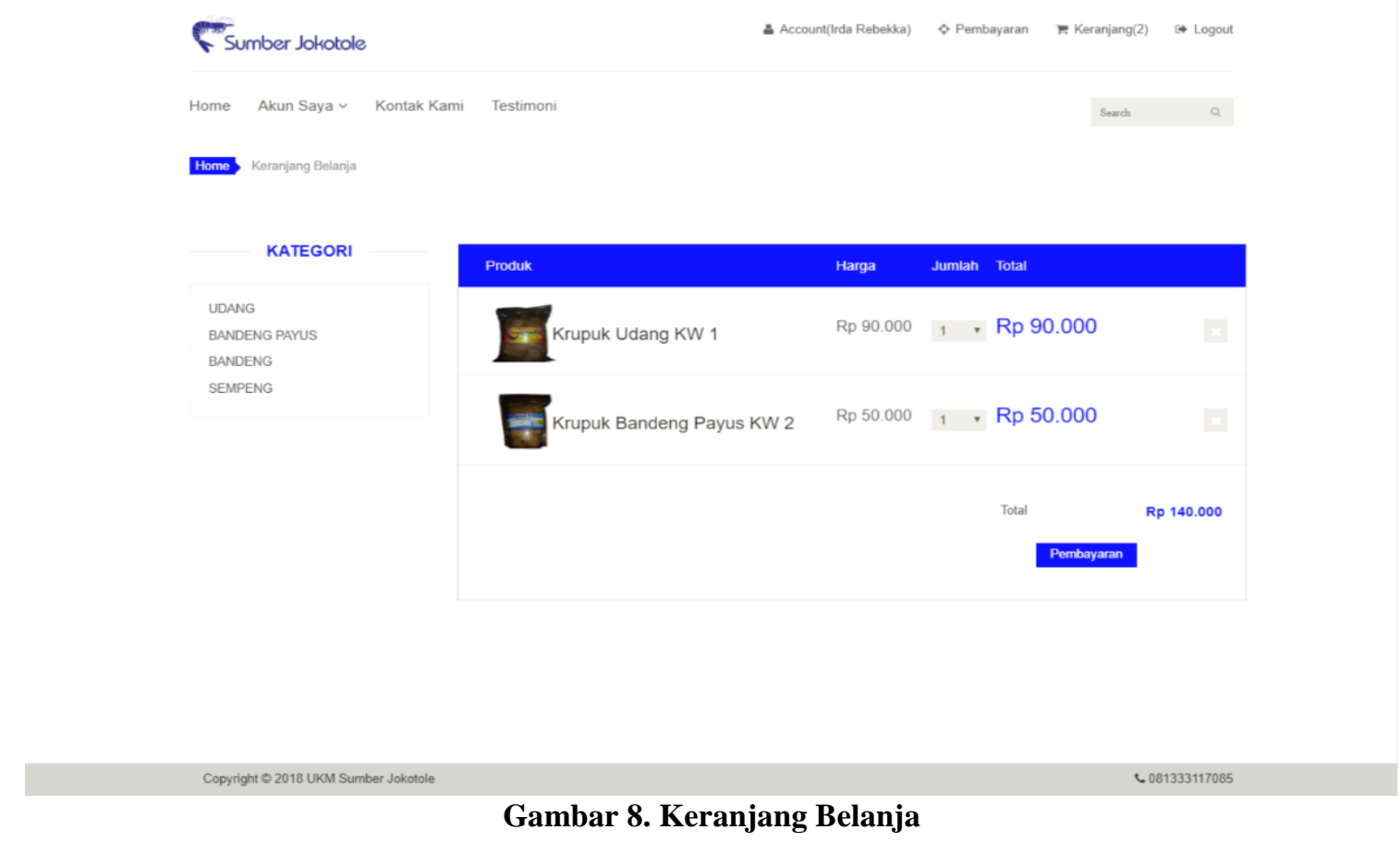

Setelah pemesanan dari konsumen telah diinput, maka selanjutnya akan melakukan pembayaran sesuai dengan harga yang telah tercantum di web tersebut dan konsumen menunggu konfirmasi dari admin atau supplier untuk melakukan penerima permintaan. 


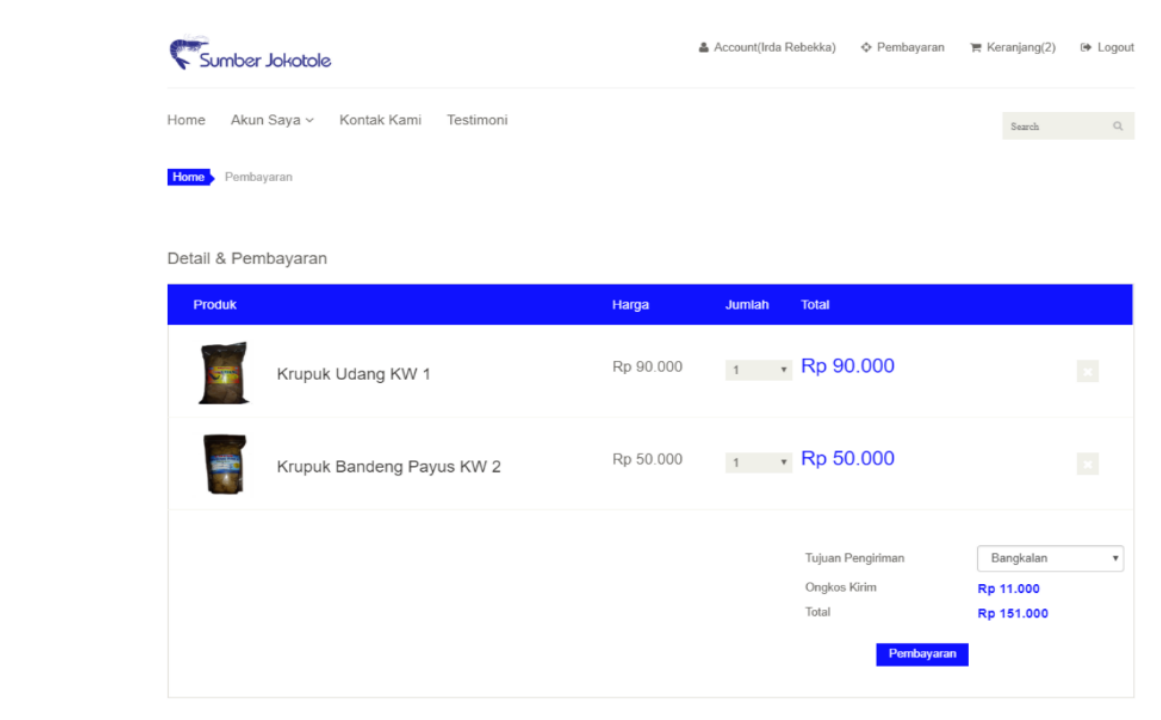

Gambar 9. Pembayaran

Setelah melakukan pembelian, maka akan melakukan pembayaran yang dilakukan oleh konsumen, dan konsumen di haruskan untuk mengisi tujuan sesuai dengan tujuan yang tersedia, kemudian akan muncul ongkos ongkir sesuai tujuan yang diinginkan, lalu akan melakukan pembayaran, kemudian akan muncul "pesanan kamu telah berhasil, tunggu konfirmasi selanjutnya".

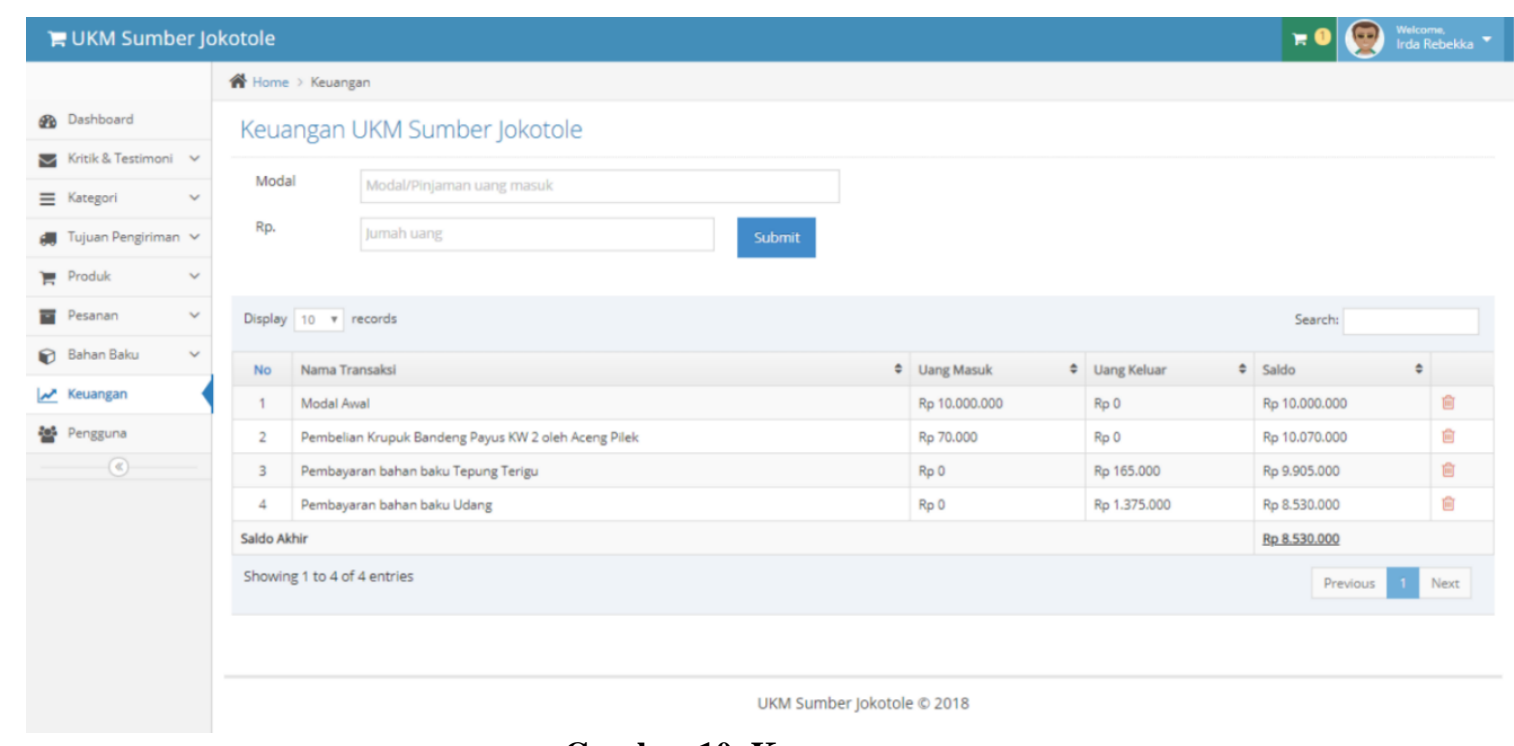

Gambar 10. Keuangan

Gambar 12 merupakan tabel keuangan yang berisi tantang modal awal yang dimiliki oleh admin, pemasukan produk penjualan yang di pasarkan pada web tersebut dan pengeluaran bahan baku yang di perlukan oleh admin amupun supplier. Pada tabel keuangan yang bisa mengelola hanya admin dan bersifat pribadi, sehingga supplier tidak dapat mengetahui masalah keuangan, dan supplier hanya bisa menginputkan data bahan bahan bahan baku dan mengkonfirmasi pemesanan dari konsumen. 


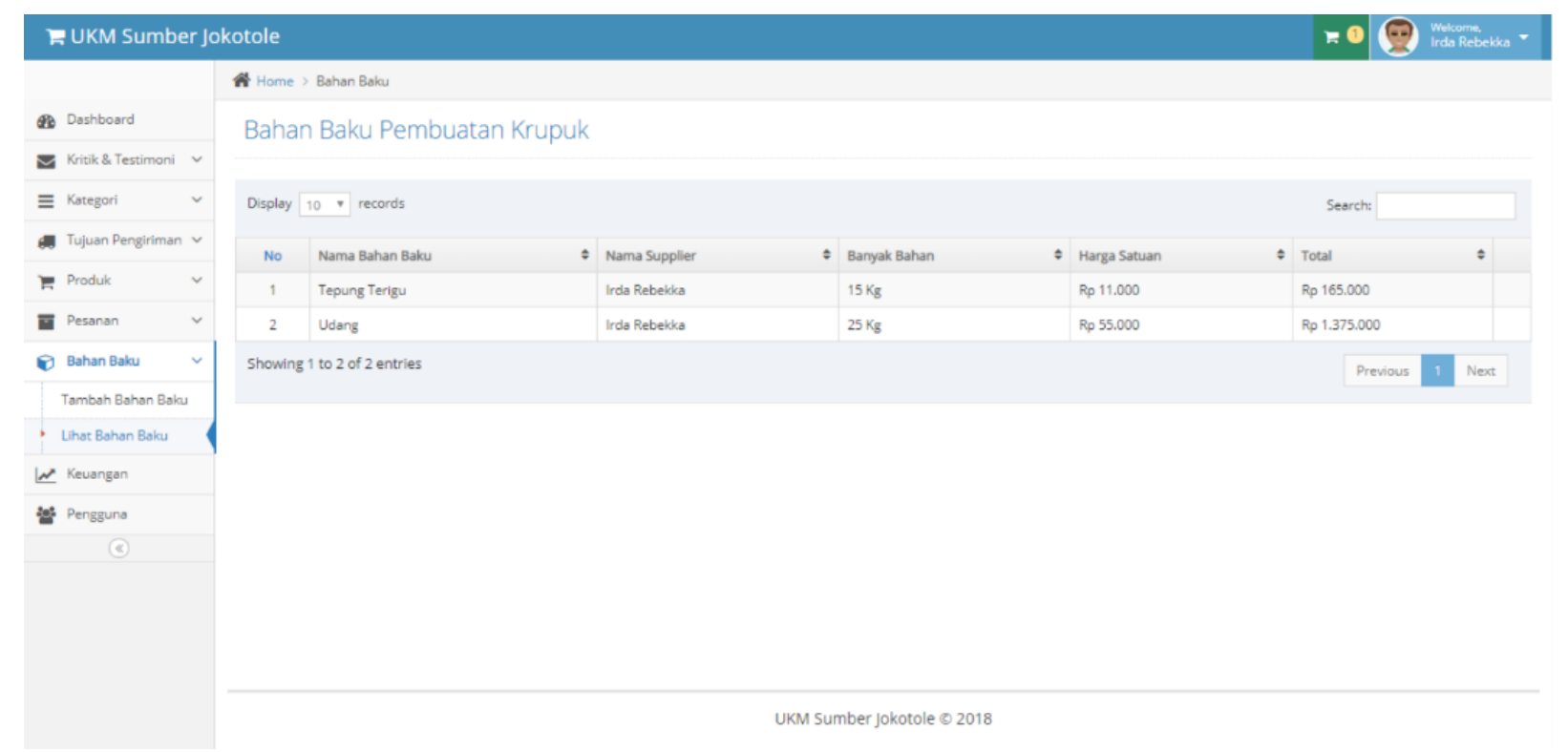

Gambar 11. Bahan Baku

\section{Kesimpulan}

Sistem informasi dapat mempermudah dalam mengontrol dan mengevaluasi bisnis kerupuk UMKM Sumber Jokotole. Pengembangan website dan e-commerce diperlukan sebagai sarana untuk promosi dan pemasaran produk-produk sehingga dapat meningkatkan penjualan dan pendapatan dan mempermudah dalam penyusunan laporan keuangan. Conceptual data model dibuat berdasarkan hubungan antar entity. Proses pembuatannya adalah membuat masing-masing entity. Entity yang dibuat yaitu entity user, entity bahan_baku, entity konfirmasi, entity produk, entity kategori, entity ongkir, entity tujuan, entity keuangan. Menghubungkan setiap entity dengan relasi dan menentukan hubungan kardinalitasnya. Melakukan pengecekan terhadap CDM yang sudah dibuat. Physical data model dibuat dengan melakukan generate physical data model pada conceptual data model yang sudah peneliti buat. Proses pembuatannya adalah CDM yang sudah dibuat kemudian di generate kedalam physical data model dan pada saat melakukan generate tentukan terlebih dahulu tipe DBMS yang akan dibuat. Tipe DBMS yang dibuat adalah MySQL 5.0, kemudian bisa melakukan situs website. Setiap penjualan dan pembelian yang dilakukan oleh suatu usaha sebaiknya dicatat dan disimpan agar tidak terjadi kesalahan saat membuat laporan keuangan dan sebaiknya suatu perusahaan menerapkan sistem Manajemen Basis Data (SMBD) dalam mengolah data-data penting agar lebih mudah dalam mengolah data-data tersebut.

\section{Acknowledgement}

Artikel ini merupakan luaran dari hasil program kemitraan masyarakat yang dibiayai oleh Kementrian Riset, Teknologi dan Pendidikan Tinggi melalui Lembaga Penelitian dan Pengabdian Kepada Masyarakat Universitas Trunojoyo Madura, Tahun anggaran 2019 dengan kontrak nomor 022/UN46.3.1/PM/2019.

\section{Referensi}

Fionita, Ita. (2015). Penerapan Sistem Informasi Manajemen Pada Usaha Kecil Menengah Di Provinsi Lampung. Lampung: Fakultas Ekonomi dan Bisnis Institut Informatika dan Bisnis Darmajaya.

Gat. (2015). Perancangan Basis Data Perpustakaan Sekolah dengan Menerapkan Model Data Relasional. STMIK Pontianak.

Ginting, N.F.H. (2011). Manajemen Pemasaran. Bandung: Yrama Widya.

Rusdiana, A., \& Irfan, M. (2014). Sistem Informasi Manajemen. Bandung: Pustaka Setia. 
Robby. (2009). Analisis dan Perancangan Basis Data untuk mendukung Aplikasi ERP Education pada Bina Nusantara University (Studi Kasus: AcademicManagementandContentPreparation). Bina Nusantara University. 